\title{
O ENSINO DE PRONÚNCIA NAS AULAS DE ESPANHOL NO COLÉGIO PEDRO II - CRENÇAS E PRÁTICAS DOCENTES
}

\author{
TEACHING PRONUNCIATION IN SPANISH CLASSES AT \\ COLÉGIO PEDRO II - TEACHING PRACTICES AND BELIEFS
}

\author{
José Ricardo Dordron de Pinho*
}

\begin{abstract}
Resumo: Este trabalho objetiva analisar o tratamento da pronúncia nas aulas de Espanhol do Colégio Pedro II. Para tanto, para um estudo qualitativo, foi aplicado um questionário a oito professores com perguntas relativas às suas crenças sobre o papel da pronúncia na comunicação, à sua formação profissional e à sua efetiva prática pedagógica. Os professores reconhecem a importância da pronúncia na comunicação. Ao considerarem sua formação profissional, no entanto, nem todos estudaram fonética e fonologia, e alguns consideram deficiente o que estudaram. Assim, nem todos se sentem preparados para desenvolver o conteúdo que, em geral, é considerado apenas durante a leitura oral dos alunos. Vale ressaltar que alguns docentes consideram pronúncia como a própria prática oral. Devido aos problemas que os professores tiveram em sua formação, fazem-se necessárias atividades de formação continuada que deem conta de tais pendências e revertam a situação a favor de um conteúdo fundamental para a comunicação oral.
\end{abstract}

Palavras-chave: Ensino de Espanhol. Pronúncia. Crenças e Práticas Docentes.

\begin{abstract}
The present paper aims at analyzing the treatment given to pronunciation in Spanish classes at Colégio Pedro II. In order to do so, for a qualitative application, the teachers of the school were given a questionnaire whose content consisted of questions related to their beliefs concerning the importance of pronunciation in communication, their vocational training and their pedagogical practice. The teachers acknowledge the importance of pronunciation for effective communication. However, when it came to their vocational training, not all of them had studied phonetics and phonology, and some of them believe that what they did study was insufficient. Therefore, not all of them feel they are prepared for developing the content (pronunciation) which is generally only tackled when students read texts aloud in class. It is important to highlight that some teachers regard pronunciation as the oral practice for itself. Due to the deficiencies teachers said to have in their vocational training, continuing education activities that can fill these gaps and reverse the situation in order to favor a content that is crucial for oral communication are of utmost importance.
\end{abstract}

Keywords: Spanish Teaching. Pronunciation. Teaching practices and beliefs.

\section{Introdução}

Este trabalho tem por objetivo refletir sobre as crenças dos professores de Espanhol do Colégio Pedro II relativas ao papel da pronúncia na comunicação, à sua formação profissional e ao ensino daquela língua na educação básica. Para tanto, aplicamos um questionário com o fim de identificar e analisar o trabalho realizado com o ensino de pronúncia do espanhol no âmbito do referido colégio. O questionário estava constituído por sete perguntas, sendo seis abertas e uma para numerar de acordo com a

\footnotetext{
* Possui graduação em Letras pela Universidade Federal do Rio de Janeiro(1994), mestrado em Letras Neolatinas pela Universidade Federal do Rio de Janeiro(2002), doutorado em Letras Neolatinas pela Universidade Federal do Rio de Janeiro(2013) e aperfeicoamento em Metodologias de pesquisa em Língua e Literatura Es pela Universidade Federal do Rio de Janeiro(1995). Atualmente é Professor do Centro Universitário Moacyr Sreder Bastos, Professor I da Secretaria Municipal de Educação - RJ, Professor do Fundação Educacional Unificada Campograndense, Professor do Colégio Pedro II, Coordenador Pedagógico do Colégio Pedro II, Coordenador Adjunto do Departamento Espanhol do Colégio Pedro II e Revisor de periódico da Khóra. E-mail: ricardodordron@ gmail.com
} 
predominância de tratamento dada a determinado tópico de ensino. Após discussões sobre o papel da pronúncia e a apresentação da metodologia, discutiremos as respostas dadas pelos oito professores às perguntas solicitadas.

\section{O papel da pronúncia na comunicação}

A pronúncia, por ser o suporte da língua oral, é o elemento que outorga inteligibilidade tanto à produção quanto à percepção da fala, de acordo com Guerrero (2010, p. 3, apud OLIVEIRA \& KAUARK, 2011).

De forma mais detalhada, Farias $(2015$, p. 2) define a pronúncia como "o conjunto dos aspectos articulatórios e perceptivos de elementos segmentais (pronúncia de vogais e consoantes) e suprassegmentais (entonação, acento, ritmo, pausas, velocidade de elocução) de uma língua". Segundo a autora, o aprendiz precisa dominar os elementos constitutivos da pronúncia para se valer satisfatoriamente de uma língua estrangeira como um instrumento de comunicação. Isso se deve ao fato de a pronúncia ser o suporte tanto da produção quanto da recepção da mensagem oral, como já havíamos visto.

Atribuindo a mesma importância a aspectos de pronúncia, Aurrecoechea (2009, p. 36) afirma que os erros cometidos pelos alunos quanto a esse aspecto podem levar a um fracasso comunicativo, uma vez que uma pronúncia inadequada torna o discurso difícil de ser compreendido por parte dos ouvintes. Além disso, podem levar aqueles a se sentirem frustrados, ainda que tenham um bom domínio dos outros aspectos da língua, pois apresentarão problemas para compreender e para serem compreendidos.

Com o fim de justificar o importante papel comunicativo desempenhado pela pronúncia, Lima Júnior (2010, p. 750) lista o que dizem três trabalhos: (1) CelceMurcia, Brinton e Goodwin (1996): se falantes não nativos se encaixarem abaixo de certo nível limiar para a pronúncia, terão problemas de comunicação oral, independentemente de terem um excelente controle da gramática e do vocabulário em inglês; (2) Morley (1994, p. 67): "pronúncia inteligível é um componente essencial da competência comunicativa"; (3) Pennington (1996, p. 2): os sons, por serem "a base de todas as unidades linguísticas superiores", são os responsáveis pela diferenciação de significado lexical, gramatical e até mesmo pragmático.

Além dessas citações, Lima Júnior (2010, p. 751) apresenta exemplos, em forma de anedotas, de situações frustrantes (e até constrangedoras) provocadas por problemas de pronúncia, dos quais apresentamos o seguinte: em "I saw a sheep in the farm" ("Eu vi uma ovelha na fazenda"), ao se substituir /i:/ por /i/, "só um sonzinho", tem-se a comunicação prejudicada, pois o falante estará dizendo que viu "um navio na fazenda", algo muito pouco provável de acontecer. Para o autor, ser inteligível é um pressuposto para uma comunicação eficaz; porém, "a falta de conhecimento fonético-fonológico da L2 aprendida pode prejudicar as tentativas de comunicação, deflagrando, assim, a necessidade de haver foco no ensino da pronúncia na sala de L2". Lima Júnior também cita Pennington (1996), para quem "o objetivo mais óbvio, justificável e urgente na área da fonologia é a inteligibilidade". Dessa forma, não se deve buscar uma "pronúncia perfeita" ou uma "pronúncia de nativo", ambos conceitos discutíveis, mas uma "pronúncia inteligível".

Gil Fernández (2007, p. 97 a 99) chega a afirmar que uma má pronúncia pode afetar a imagem do falante. Quem fala uma LE com considerável fluência mas mantém um forte sotaque da sua LM pode fazer com que, aos olhos dos outros, tudo aquilo seja 
esquecido. A comunidade estrangeira pode dar um maior acolhimento ao imigrante se ele se aproximar ao padrão nativo. Uma má pronúncia do idioma pode ir de uma ligeira impaciência ante a lentidão até uma grande irritação. Podem considerar como despreocupação ou até desprezo pela nova língua. A autora cita o trabalho de Zuengler (1988, p. 35), que lista o resultado de várias pequenas pesquisas que comprovam que "hablantes de inglés con acento español son sistemáticamente minusvalorados en los Estados Unidos, tanto en las entrevistas laborales como en las instancias académicas"). Em síntese, aprimorar a pronúncia é de suma importância, não apenas para a comunicação verbal.

\section{Sobre a prática do ensino da pronúncia}

A importância da pronúncia nas aulas de línguas estrangeiras variou muito ao longo do tempo, recebendo grande atenção em alguns momentos, mas tendo sido completamente ignorada em outros; esta última é a situação predominante, ainda que, em geral, se atribua grande importância à oralidade.

Aurrecoechea (2009) desenvolveu uma pesquisa com 19 professores nativos de Espanhol que atuam em escolas e universidades da Europa e da América. Segundo a autora (p. 21), os professores valorizam bastante a compreensão e a expressão oral, mas dedicam pouco tempo à pronúncia. Os possíveis motivos para o tratamento da pronúncia ser um assunto pendente nas aulas seria a falta de bibliografia e de materiais especializados, o que levaria a uma formação deficiente dos professores, que se sentiriam inseguros quanto ao tema (p. 3).

Não tivemos acesso a trabalhos desse tipo quanto ao ensino de Espanhol no Brasil, mas sim quanto ao Inglês: Bollela (2002 apud SOUZA 2009, p. 24) constata que, em nosso país, os alunos de inglês se queixam da qualidade de sua pronúncia e também os professores se sentem inseguros quanto à sua própria pronúncia. Para a autora, tal fato ocorre por o processo de ensino-aprendizagem se dar predominantemente por meio da escrita e não de imersão. Outro fato importante relatado por Bollela (2002, p. 42) é que a pronúncia, como componente da comunicação oral, está recebendo cada vez mais atenção na literatura sobre ensino de línguas, mas "os livros didáticos, em sua maioria, não refletem esse interesse. O que se encontra são atividades voltadas para a fala ou para a compreensão auditiva e não para a pronúncia propriamente dita".

Derwing e Munro (2005, apud USÓ VISIEDO 2008, p. 107) comentam o fato de muitos professores não terem tido nenhuma preparação formal para ensinar pronúncia; como consequência, os alunos não recebem nenhuma instrução ou o ensino se focaliza em traços muito específicos, "sin tener en cuenta su influencia en la inteligibilidad". $\mathrm{O}$ resultado dessa situação é que os materiais e as práticas dos professores ainda se encontram sob influência do senso comum e da intuição, já que não contam com uma direção. Diante desse fato, é possível que professores não se sintam à vontade para trabalhar o assunto em questão.

Poch Olivé (2008) apresenta os resultados de um experimento desenvolvido por Elliott (1997): o experimento foi realizado com 66 estudantes em dois grupos, um experimental e um de controle (no primeiro, a pronúncia foi tratada de forma 
específica). O resultado observado foi o seguinte: o tratamento da pronúncia em aula contribuiu para o desenvolvimento dos alunos e, portanto, é benéfico, "porque favorece la comprensión de los enunciados emitidos por los nativos e incide sobre el filtro afectivo del alumno, haciendo disminuir su sensación de ansiedad con respecto a la comunicación oral". Daí se comprovam os benefícios que o ensino de pronúncia traz para o desenvolvimento das habilidades orais.

\section{Metodologia}

Considerando que o objetivo do trabalho é identificar crenças e práticas relacionadas ao ensino da pronúncia da língua espanhola no Colégio Pedro II, elaboramos um questionário constituído por 7 questões para os professores de Espanhol do referido ambiente escolar. O questionário foi encaminhado por e-mail a todos os professores do departamento, no início de 2017, nessa época formado por 19 docentes (18 efetivos e 1 contratado). Esperávamos obter 18 respostas, uma vez que a chefe do departamento não deveria participar da pesquisa, por não ter atuado em sala de aula no ano letivo de 2016, ano base para a análise dos dados. No entanto, obtivemos respostas de apenas 8 professores ( 7 efetivos e 1 contratado). Esse fato limita nossa análise, por não podermos obter uma visão do colégio como um todo, mas não a inviabiliza. Realizamos, assim, um estudo quantitativo sobre o assunto. seguir:

Como dito, foram solicitadas respostas para sete perguntas, apresentadas a

1 - Você acredita que uma pronúncia deficiente possa prejudicar a comunicação? Por quê? Como?;

2 - Em sua opinião, o ensino de pronúncia é importante? Por quê?;

3 - Durante a sua formação, você cursou alguma matéria específica relativa à pronúncia ou à fonética/fonologia da língua espanhola? Em caso afirmativo, comente a experiência;

4 - Caso tenha tido, como você classifica o ensino de pronúncia que teve durante sua formação? Foi suficiente ou seus professores focaram pouco nesse assunto?;

5 - Você se sente preparado para ensinar pronúncia?;

6 - Na sua prática de ensino de Espanhol no Colégio Pedro II, no ano de 2016, o que você priorizou em suas aulas? (Numere de maior [1] a menor [7] dedicação de tempo - marque um $\mathrm{X}$ caso você não tenha trabalhado o tópico ou o tenha feito de maneira muito pouco frequente) [as opções eram "Compreensão auditiva", "Gramática", "Léxico", "Pronúncia", "Expressão oral”, "Compreensão escrita" e "Expressão escrita"];

7 - Caso você tenha trabalhado a pronúncia com seus alunos no Colégio Pedro II no ano de 2016, explique como e indique a frequência.

$\mathrm{O}$ e-mail enviado aos professores com o questionário foi acompanhado de uma explicação sobre a pesquisa, com as possíveis contribuições que poderia trazer. Não houve apresentação da pesquisa a um Comitê de Ética, mas todos os envolvidos autorizaram o uso de suas informações. A seguir, apresentamos o que esperávamos de cada pergunta e a análise realizada a partir das respostas dos entrevistados.

\section{Análise dos dados obtidos em questionário}


Para a análise dos dados, transcrevemos as respostas dadas a cada uma das perguntas pelos entrevistados, tal como foram escritas, e tecemos comentários sobre as mesmas.

A primeira pergunta, "Você acredita que uma pronúncia deficiente possa prejudicar a comunicação? Por quê? Como?", busca identificar se os entrevistados reconhecem o papel primordial que a pronúncia desempenha na comunicação oral e os problemas comunicativos decorrentes de problemas nesse nível, uma vez que a pronúncia é a base da oralidade.

\begin{tabular}{|c|c|}
\hline 1 & $\begin{array}{l}\text { Depende do que se acredita por "deficiente". A pronúncia sem dúvida faz parte da língua falada. Mas } \\
\text { também é lógico que um falante L2 nunca vai falar como um nativo, nem deveria ter que seguir esse } \\
\text { objetivo como muitos fazem. Num primeiro momento o contato com um sotaque diferente do que se } \\
\text { está acostumado pode gerar estranheza, mas somos animais que dominamos a língua, então, com a } \\
\text { prática, ambos podem se entender. Temos também a questão da identidade cultural que pode } \\
\text { influenciar, como os falantes que não aceitam escutar sua língua sendo falada com outro sotaque, as } \\
\text { questões sociais também fazem parte dessa questão. }\end{array}$ \\
\hline 2 & $\begin{array}{l}\text { Sim, pois causa ruídos na comunicação, além do fato da desmotivação do interlocutor ao não conseguir } \\
\text { compreender o que lhe é dito. }\end{array}$ \\
\hline 3 & $\begin{array}{l}\text { Acredito que sim, ainda que não tão definitivamente assim. Creio que uma falha muito grave na } \\
\text { comunicação pode causar distanciamento entre os falantes, criando noções de hierarquia, formações } \\
\text { entre eles. Uma pronúncia deficiente pode permitir a comunicação, mas pode ocasionar ruídos para } \\
\text { além da compreensão. Por outro lado, a busca de uma pronúncia perfeita é também uma utopia. }\end{array}$ \\
\hline 4 & $\begin{array}{l}\text { Sim. Existem sons que existem em uma língua e não existem na outra. Além disso, os sons podem ter } \\
\text { um diferente papel fonético-fonológico nas línguas em questão. Assim, problemas de pronúncia podem } \\
\text { chegar a impedir a comunicação e/ou provocar situações de compreensão equivocada. }\end{array}$ \\
\hline 5 & Sim, por comprometer a compreensão. \\
\hline 6 & $\begin{array}{l}\text { Pensando em um contexto mais amplo, acredito que dependerá se este problema de pronúncia ocasiona } \\
\text { ou não um ruído na comunicação, de forma a impedir o entendimento da mensagem transmitida. } \\
\text { Assim, uma pronúncia deficiente pode figurar como empecilho quando impossibilita a compreensão e a } \\
\text { interação. } \\
\text { No mais, centrando-nos no ambiente escolar, acredito que, a depender do nível de ensino e do contexto } \\
\text { de aprendizagem, aquilo que se diz importa mais do que o como se diz, o que não nega de forma } \\
\text { alguma a importância do desenvolvimento da pronúncia nas aulas de LE. }\end{array}$ \\
\hline 7 & Aqui fiquei com dúvida sobre o que seria uma "pronúncia deficiente". \\
\hline 8 & $\begin{array}{l}\text { Sim. Para haver comunicação, é preciso que haja entendimento entre o falante e o ouvinte de } \\
\text { determinada língua, o que só ocorrerá se o usuário fizer uma correta articulação e reprodução dos sons } \\
\text { da língua em uso. Em outras palavras, se pronunciá-la em condições que possibilitem a comunicação e } \\
\text { viabilize o entendimento. }\end{array}$ \\
\hline
\end{tabular}

Tabela 1. Respostas à pergunta 1: "Você acredita que uma pronúncia deficiente possa prejudicar a comunicação? Por quê? Como?".

Com exceção do sétimo entrevistado, que não entendeu o sentido de "pronúncia deficiente", todos os demais consideram que problemas de pronúncia podem interferir no processo comunicativo. Essa opinião reflete o reconhecimento do papel fundamental da pronúncia na comunicação oral e corresponde ao que vimos em Guerrero (2010, apud OLIVEIRA \& KAUARK, 2011), para quem a pronúncia outorga inteligibilidade à comunicação. O reconhecimento da importância da pronúncia para a comunicação nos leva a supor que, caso os entrevistados trabalhem com as habilidades orais, incluirão o tema em suas aulas, o que comprovaremos mais adiante. Além do reconhecimento da importância da pronúncia, alguns entrevistados fizeram comentários que merecem uma discussão.

Os entrevistados 1 e 3 comentam a questão da "pronúncia perfeita". Como já vimos, esse conceito é bastante discutível: quais seriam o modelo e os falantes 
“perfeitos"? O que se busca, efetivamente, é uma pronúncia inteligível, que não afete a comunicação (PENNINGTON, 1996, apud LIMA JR., 2010). Assim, torna-se muito importante o tópico levantado pelos professores: numa aula de pronúncia, não se deve realizar com os alunos uma prática que leve à exaustão pela busca do "perfeito", mas sim chegar a um nível de pronúncia que não comprometa a comunicação.

O entrevistado 1 ainda traz à tona a questão da identidade cultural: como ele diz, ouvir uma pronúncia diferente pode afastar o falante nativo da língua, entre outras razões, por considerar que o estrangeiro não dá a devida importância à sua língua (como disse Gil Fernández (2007), uma má pronúncia pode afetar a imagem do falante); esse tema é comentado também pelo entrevistado 2 , ao considerar a desmotivação do falante nativo, por não ter paciência para esperar por uma fala mais lenta e pausada. Ambas as situações realmente podem acontecer, mas o oposto também: o nativo pode acabar sendo mais paciente, por saber que se trata de um não nativo e reconhecer as dificuldades advindas dessa situação.

Outro tema importante a ser discutido aqui é o introduzido pelo entrevistado 6: ainda que problemas de pronúncia possam afetar a comunicação, nem sempre isso ocorre. De maneira geral, deficiências em nível segmental são menos problemáticas, muitas vezes solucionadas pelo próprio contexto ou pela prosódia; neste último nível sim os problemas são mais complicados de resolver. Daí as críticas tão comuns feitas às coleções didáticas: o que predomina é que só se trabalhem questões segmentais ou que essas sejam trabalhadas antes das prosódicas. De acordo com os especialistas, a prosódia deve ser trabalhada primeiramente ou, pelo menos, ser trabalhada de forma concomitante aos aspectos segmentais.

A pergunta 2, "Na sua opinião, o ensino de pronúncia é importante? Por quê?", está relacionada à primeira, que tratava da importância da pronúncia para a comunicação. A diferença é que a pergunta 2 remete a uma questão pedagógica: a necessidade de didatizar o conteúdo pronúncia, muitas vezes descartado (geralmente, por falta de material e/ou de conhecimento).

\begin{tabular}{|l|l|}
\hline 1 & Sim, pois a pronúncia faz parte da língua e da cultura dos falantes. \\
\hline 2 & Sim, porque é condição sine qua non no aprendizado de línguas. \\
\hline 3 & $\begin{array}{l}\text { Sim. No sentido de que adquirir uma língua é também se aproximar de uma cultura - estamos falando } \\
\text { de algo mais do que uma ferramenta }- \text {, reconhecer as curvas desta cultura pode significar uma melhor } \\
\text { aproximação, e aceitação, do usuário. }\end{array}$ \\
\hline 4 & $\begin{array}{l}\text { Sim, porque traz benefícios para uma comunicação efetiva; problemas de pronúncia podem impedir } \\
\text { uma plena comunicação. }\end{array}$ \\
\hline 5 & Se o objetivo for expressão oral, sim, pois ( oentrevistado não concluiu sua resposta) \\
\hline 6 & $\begin{array}{l}\text { É importante, pois figura como parte integradora de competências requeridas quando do ensino de } \\
\text { línguas se trata. Além desse dado mais curricular, acredito que o desenvolvimento da pronúncia em sala } \\
\text { mostra-se como um interessante caminho de aproximação afetiva do aprendiz com a língua estrangeira. }\end{array}$ \\
\hline 7 & $\begin{array}{l}\text { Sim. Na medida do possível, creio que devemos enfatizar a pronúncia em nossas aulas. Dessa forma, o } \\
\text { aluno terá um aprendizado mais completo da língua. }\end{array}$ \\
\hline 8 & $\begin{array}{l}\text { Sim. Ao considerarmos que a língua é uma manifestação essencialmente oral, é relevante que o aluno } \\
\text { domine a linguagem oral e, para tanto, é necessário que exercite a pronúncia. }\end{array}$ \\
\hline
\end{tabular}

Tabela 2. Respostas à pergunta 2: "Na sua opinião, o ensino de pronúncia é importante? Por quê?’"

Ao tratar da importância do ensino de pronúncia, os professores são unânimes em apresentar uma resposta afirmativa. Como visto anteriormente, a pronúncia é parte integrante da língua e, se não for trabalhada em sala, pode levar a incompreensões ou à falta de comunicação. Vale lembrar o que disse o professor 8: "a língua é uma 
manifestação essencialmente oral"; justamente por essa razão, a pronúncia se torna um componente fundamental no trabalho com a oralidade.

Vale considerar, também, o que disse o entrevistado 5, que, apesar de não ter concluído sua resposta, chegou a mencionar que a pronúncia deve estar presente nas aulas de línguas estrangeiras SE o objetivo for a expressão oral (incluiríamos aí a compreensão oral) - é importante considerar o trabalho com as habilidades orais pelo fato de, muitas vezes, só se trabalhar compreensão leitora; dessa forma, a pronúncia não traria grandes contribuições para o objetivo dessas aulas. No entanto, torna-se necessário destacar que, em pesquisas prévias, os professores atribuem grande importância à pronúncia, mas excluem o conteúdo de suas aulas ou lhe dedicam muito pouco tempo, alegando pouco conhecimento sobre o assunto e/ou falta de material didático disponível no mercado, como visto no trabalho de Aurrecoechea (2007).

Mais adiante, veremos se os professores entrevistados neste trabalho, a partir da consideração de que problemas de pronúncia podem afetar a comunicação e que seu ensino é importante no estudo de uma língua estrangeira, incluem o tema em suas aulas.

A pergunta 3, "Durante a sua formação, você cursou alguma matéria específica relativa à pronúncia ou à fonética/fonologia da língua espanhola? Em caso afirmativo, comente a experiência", objetiva identificar se os entrevistados receberam uma formação fonético-fonológica, isto é, se sua formação contou com alguma disciplina que pudesse lhes oferecer subsídios para a prática do ensino da pronúncia. O conteúdo das respostas a essa pergunta será retomado mais adiante, quando analisarmos a prática pedagógica de cada entrevistado na escola; acreditamos que deixar de trabalhar pronúncia pode estar relacionado a uma formação inexistente ou deficiente.

\begin{tabular}{|l|l|}
\hline 1 & Sim. Foi muito proveitosa e rica, aulas interessantes. \\
\hline 2 & Sim, mas se limitou a parte teórica. \\
\hline 3 & Não. Minha pronúncia (e seus defeitos) vem da convivência com nativos (padrasto uruguaio). \\
\hline 5 & $\begin{array}{l}\text { Sim. Foi trabalhado fonema por fonema da língua espanhola, com suas realizações fonéticas e } \\
\text { representações ortográficas, além das dificuldades de falantes do PB nos três níveis (fonológico, } \\
\text { fonético e ortográfico). }\end{array}$ \\
\hline 6 & $\begin{array}{l}\text { Não. Somente uma disciplina de conversação que, por não ser obrigatória, tinha uma frequência muito } \\
\text { baixa. }\end{array}$ \\
\hline 7 & $\begin{array}{l}\text { Sim. Foi uma experiência muito enriquecedora, principalmente no que diz respeito a uma maior } \\
\text { conscientização, durante a graduação, sobre a diversidade linguística que é constituinte da língua } \\
\text { espanhola. }\end{array}$ \\
\hline 8 & $\begin{array}{l}\text { Durante a formação, tive aulas de "conversação" em espanhol (2 tempos semanais) do primeiro ao } \\
\text { terceiro período. Nesses encontros, havia debates acerca de temas diversos e apresentações de trabalhos } \\
\text { em duplas/grupos. Cursei, ainda, "Fonética e Fonologia" durante o quarto período da faculdade. Nas } \\
\text { aulas dessa disciplina específica, foram abordados, de forma geral, alguns aspectos gerais do espanhol } \\
\text { falado na Espanha e na América Latina. }\end{array}$ \\
\hline $\begin{array}{l}\text { Cursei fonética e fonologia da língua espanhola. Porém, foi um período muito curto e a disciplina foi } \\
\text { muito pouco trabalhada; deficiente. A experiência poderia ter sido melhor e mais significativa. } \\
\text { Lembro-me muito mais das aulas de fonética e fonologia do português. O conteúdo foi muito mais } \\
\text { detalhado e extenso. }\end{array}$ \\
\hline
\end{tabular}

Tabela 3. Respostas à pergunta 3: "Durante a sua formação, você cursou alguma matéria específica relativa à pronúncia ou à fonética/fonologia da língua espanhola? Em caso afirmativo, comente a experiência".

Dois entrevistados (3 e 5) afirmam categoricamente que não tiveram aulas de pronúncia e/ou de fonética e fonologia do espanhol. O segundo deles disse que teve aulas de conversação, o que não é a mesma coisa. $O$ entrevistado 7 , a ser comentado em seguida, também fez referência às aulas de conversação. Depreende-se, desses dois 
comentários, que muitos professores veem a pronúncia como prática oral, quando, na verdade, é apenas uma base, um suporte para ela.

Todos os demais 6 entrevistados disseram que tiveram aulas de pronúncia e/ou de fonética e fonologia do espanhol; no entanto, cinco deles deixam perceber deficiências. O entrevistado 2 só teve acesso à parte teórica. O entrevistado 6 associa o conteúdo à variação linguística; ainda que exista, naturalmente, a variação fonéticofonológica, esse foco limita bastante seu campo de atuação. O entrevistado 7, já mencionado anteriormente, afirma que suas aulas se limitaram à caracterização de variedades do espanhol. $O$ entrevistado 8 comenta que o período foi curto e que o tema não foi trabalhado da melhor forma. Por fim, o entrevistado 4 é o que parece ter tido a base mais sólida do tema em questão; porém, ainda que tenha estudado detalhadamente os fonemas do espanhol, suas realizações fonéticas e representações ortográficas, considerando as dificuldades do falante brasileiro, seu estudo se limitou ao aspecto segmental - nada de prosódia, o nível mais importante, foi trabalhado.

O entrevistado 1 confirmou ter tido aulas do tema em questão, mas, ao comentar, se limita a qualificar, de maneira positiva, o curso, afirmando que as aulas foram proveitosas e interessantes, de forma de não podemos analisar o conteúdo abordado.

Cremos que, a partir da formação apresentada, os entrevistados refletirão em sua prática docente as dificuldades decorrentes de dita formação: é provável que também excluam a pronúncia de suas aulas ou a trabalhem superficialmente. Esse foi o resultado da pesquisa de Aurrecoechea (2009), em que os professores entrevistados valorizam a oralidade, mas dedicam pouco tempo à pronúncia, alegando falta de bibliografia e de materiais específicos. Comprovaremos nossas hipóteses mais adiante.

A pergunta 4, "Caso tenha tido, como você classifica o ensino de pronúncia que teve durante sua formação? Foi suficiente ou seus professores focaram pouco nesse assunto?", busca identificar como foi a formação fonético-fonológica dos entrevistados que a tiveram, ou seja, se sua formação lhe ofereceu subsídios para uma efetiva prática do ensino da pronúncia. Assim como comentamos na introdução à análise dos dados da pergunta anterior, o conteúdo destas respostas também será retomado mais adiante, ao analisarmos a prática pedagógica de cada entrevistado na escola; além de acreditarmos que deixar de trabalhar pronúncia pode estar relacionado a uma formação inexistente, o mesmo pode ocorrer por conta de uma formação deficiente.

\begin{tabular}{|l|l|}
\hline 1 & Foi suficiente. \\
\hline 2 & Foi bem superficial. Não houve muito aprofundamento na área. \\
\hline 3 & $\begin{array}{l}\text { Não tive e meus professores jamais tiveram esta preocupação. Inclusive, alguns professores marcavam } \\
\text { o território de brasileiros falantes da língua espanhola. Isso parece ser uma bandeira política. }\end{array}$ \\
\hline 4 & $\begin{array}{l}\text { Foi bastante completo, no sentido de que trabalhamos a parte teórica e realizamos diversas atividades } \\
\text { práticas. }\end{array}$ \\
\hline 5 & $\mathrm{X}$ \\
\hline 7 & $\begin{array}{l}\text { Classifico como bom, tendo em vista a possiblidade de contato com reflexões sobre a variação } \\
\text { linguística da língua, como antes citado. Acredito que sempre há possibilidade de debruçarmo-nos mais } \\
\text { sobre o tema. }\end{array}$ \\
\hline 8 & $\begin{array}{l}\text { Considero o ensino bom, de acordo com a proposta do curso, que não era a de aprofundar muito } \\
\text { questões relativas à fonética e à fonologia. A formação foi mais voltada para aspectos discursivos da } \\
\text { língua. }\end{array}$ \\
\hline $\begin{array}{l}\text { Deficiente. Focaram pouco; não havia um laboratório específico para exercitarmos a oralidade e } \\
\text { termos experiências com diferentes pronúncias. }\end{array}$ \\
\hline
\end{tabular}

Tabela 4. Respostas à pergunta 4: "Caso tenha tido, como você classifica o ensino de pronúncia que teve durante sua formação? Foi suficiente ou seus professores focaram pouco nesse assunto?" 
Como observado na questão anterior, dois entrevistados (3 e 5) afirmaram não terem tido aulas de pronúncia, razão pela qual o entrevistado 5 nem respondeu a pergunta. $\mathrm{O}$ entrevistado 3 a respondeu, para enfatizar que o assunto foi completamente ignorado pelos professores, devendo-se, talvez, a uma questão política.

Dentre os 6 professores que afirmaram terem tido aulas de pronúncia, três deles (1, 2 e 8) consideram sua formação insuficiente. Apenas os outros três (4, 6 e 7) consideram sua formação como boa, com atividades teóricas e práticas e com reflexão sobre o assunto. $\mathrm{O}$ entrevistado 7 , no entanto, chega a comentar que o ensino foi bom se se considerar a proposta do curso, que não buscava um grande aprofundamento no assunto. Em síntese, poucos tiveram acesso a um estudo aprofundado sobre o tratamento da pronúncia, o que pode refletir negativamente em sua prática pedagógica, inclusive por problemas de insegurança na própria pronúncia, como visto em Bollela (2002, apud Souza, 2009).

A $5^{\text {a }}$ pergunta, "Você se sente preparado para ensinar pronúncia?", pretende identificar como os entrevistados se sentem com relação às suas condições de trabalhar com o tema em tela. Para tanto, devido à formação inexistente ou insuficiente de alguns deles, haveria necessidade de uma formação posterior à inicial. Na análise das respostas à pergunta 5, retomaremos as respostas das duas questões anteriores.

\begin{tabular}{|l|l|}
\hline 1 & Sim. \\
\hline 2 & $\begin{array}{l}\text { Não com aprofundamento. Somente para uma leitura com correção e dentro dos padrões "universais" } \\
\text { do idioma. }\end{array}$ \\
\hline 3 & Não. Mas me sinto bem próximo da prosódia Uruguaia-Portenha. \\
\hline 4 & Sim, por conta da base que tive. \\
\hline 5 & $\begin{array}{l}\text { Não. No máximo, ressaltar algumas características e diferenças na pronúncia de alguns países e orientar } \\
\text { a fala dos alunos. }\end{array}$ \\
\hline 6 & $\begin{array}{l}\text { Prefiro acreditar que estou em um contínuo processo de preparação, uma constante autoconstrução } \\
\text { como docente. }\end{array}$ \\
\hline 7 & \begin{tabular}{l} 
Depende da proposta a ser praticada. Se for para abordar pronúncia de forma mais geral, sim. \\
\hline 8
\end{tabular} \\
$\begin{array}{l}\text { Com grupos grandes, turmas de } 20 \text { e } 30 \text { alunos, sinto um pouco de dificuldade. Em cursinhos de } \\
\text { línguas, o trabalho com a oralidade era mais dinâmico e eu sabia conduzir melhor as atividades que } \\
\text { envolviam tal habilidade. }\end{array}$ \\
\hline
\end{tabular}

Tabela 5. Respostas à pergunta 5: "Você se sente preparado para ensinar pronúncia?"

Dentre os 8 professores entrevistados, apenas 2 afirmam, categoricamente, que se sentem preparados para ensinar pronúncia. Um deles (4) justifica o fato considerando a base que teve; o outro (1) apenas disse que sim. Considerando os demais 6 entrevistados, um diz que, efetivamente, não se sente preparado (3). Os demais creem conseguir desenvolver tal prática de forma genérica ou apenas em situações específicas: só de maneira muito ampla, sem entrar em detalhes (2 e 7), apenas para tratar de diferenças de pronúncia (5) ou apenas em grupos menores (8). O entrevistado 6 considera que está em um constante processo de formação docente, o que é determinante para compensar as lacunas da formação.

Ao considerarmos as respostas à pergunta 5 relacionando-as às perguntas 3 e 4, percebemos que os entrevistados $2,3,5$ e 8 são os que ou não se sentem preparados para ensinar pronúncia ou se sentem pouco preparados para essa atividade. Ao considerar as respostas que esses mesmos entrevistados deram às perguntas 3 e 4 , fica fácil entender o porquê: formação inexistente ou deficiente, tal como relatado neste trabalho na discussão teórica. 
A pergunta 6 era a seguinte: "Na sua prática de ensino de Espanhol no Colégio Pedro II, no ano de 2016, o que você priorizou em suas aulas? (Numere de maior [1] a menor [7] dedicação de tempo - marque um $X$ caso você não tenha trabalhado o tópico ou o tenha feito de maneira muito pouco frequente):

( ) Compreensão auditiva.

( ) Gramática.

( ) Léxico.

( ) Pronúncia.

( ) Expressão oral.

( ) Compreensão escrita.

( ) Expressão escrita.

A pergunta 6 pretende identificar as prioridades que os professores tiveram em suas aulas no Colégio Pedro II em 2016 (explicaremos, nos comentários à pergunta 7, o porquê de nos determos em um ano específico). São consideradas as 4 habilidades linguísticas, além dos conteúdos linguísticos que dão suporte a elas (gramática, léxico e pronúncia).

\begin{tabular}{|c|c|c|c|c|c|c|c|}
\hline & $\begin{array}{c}\text { COMPR. } \\
\text { AUD. }\end{array}$ & $\begin{array}{c}\text { GRAMÁ- } \\
\text { TICA }\end{array}$ & LÉXICO & $\begin{array}{c}\text { PRONÚN- } \\
\text { CIA }\end{array}$ & EXPR. OR. & $\begin{array}{c}\text { COMPR. } \\
\text { ESCR. }\end{array}$ & $\begin{array}{c}\text { EXPR. } \\
E S C R .\end{array}$ \\
\hline 1 & 4 & 1 & 2 & 7 & 6 & 3 & 5 \\
\hline 2 & $\mathrm{X}$ & 1 & $\mathrm{X}$ & $\mathrm{X}$ & $\mathrm{X}$ & 2 & 3 \\
\hline 3 & 6 & 2 & 3 & 4 & 5 & 1 & $\mathrm{X}$ \\
\hline 4 & 6 & 3 & 5 & 4 & 2 & 1 & $\mathrm{X}$ \\
\hline 5 & $\mathrm{X}$ & 4 & 2 & $\mathrm{X}$ & $\mathrm{X}$ & 1 & 3 \\
\hline 6 & 6 & 1 & 4 & 3 & 5 & 1 & 2 \\
\hline 7 & 7 & 3 & 2 & 5 & 6 & 1 & 4 \\
\hline 8 & 4 & 2 & 3 & 6 & 5 & & 1 \\
\hline
\end{tabular}

Tabela 6. Numeração relativa à ordem de prioridades nas aulas de Espanhol dos professores entrevistados (em verde, destacamos duas vezes o número 1 atribuído por um dos entrevistados, por considerar a mesma frequência a dois itens).

Destacamos, em verde, o fato de um participante ter numerado " 1 " para dois itens, por considerar trabalhá-los na mesma proporção.

Ao considerar o que é prioridade nas aulas de Espanhol do Colégio Pedro II a partir das respostas dos 8 professores entrevistados, verificamos que dois deles (2 e 5) ignoram por completo a prática das habilidades orais e, consequentemente, da pronúncia. É possível que tal ausência se deva a ambos os professores considerarem não terem tido uma formação fonético-fonológica adequada e não se sentirem preparados para esse trabalho. Lembremos o comentário de Derwing e Munro (2005, apud USÓ VICIEDO, 2008), de que, se os professores, em sua formação, não receberam uma preparação formal quanto ao tratamento da pronúncia, é comum que eliminem o assunto por completo.

Nos demais professores, com uma única exceção (entrevistado 4, quanto a pronúncia e expressão oral), a atenção sempre é maior para a compreensão escrita, a gramática e o léxico; as duas habilidades orais e a pronúncia ocupam as últimas posições quando se considera o tempo dedicado às atividades, perdendo, apenas em alguns casos, para a expressão escrita (que também não é trabalhada por dois professores). 
Constatamos, então, o desprestígio dado à oralidade, que, no entanto, é o objetivo da maior parte dos alunos (PINHO, 2017). Ao observar esse resultado, pensamos em uma pergunta que poderíamos ter feito na ocasião da aplicação do questionário - o porquê do menor tempo para a parte oral. Cremos, no entanto, que essa situação esteja relacionada a problemas na formação docente ou a uma prática bastante comum no ensino de língua, que prioriza a língua escrita e a tradição gramatical.

Ao responderem a questão 6, foi aberto um espaço para que os entrevistados tecessem comentários, se assim o desejassem. Como se observa na tabela 7, apenas 5 dos 8 entrevistados escreveram algo.

\begin{tabular}{|c|c|}
\hline 1 & $\begin{array}{l}\text { As respostas da questão } 6 \text { não representam o que minha base teórica e eu acreditamos como o melhor } \\
\text { para o ensino de espanhol, porém, devido a seguir o programa preestabelecido, foi necessário abrir mão } \\
\text { do que sei fazer melhor, do que considero como educação de qualidade. }\end{array}$ \\
\hline 2 & $\mathrm{X}$ \\
\hline 3 & Compreensão escrita seria capacidade leitora? Se for, este foi o critério que mais trabalhei: 7 \\
\hline 4 & $\mathrm{X}$ \\
\hline 5 & $\begin{array}{l}\text { As características das turmas inviabilizam qualquer trabalho de compreensão auditiva ou expressão } \\
\text { oral. }\end{array}$ \\
\hline 6 & $\begin{array}{l}\text { Fazendo uma autoanálise (autocrítica), acredito que possa atribuir } 1 \text { tanto à gramática quando à } \\
\text { compreensão escrita, se considero como critério a dedicação de tempo das aulas. }\end{array}$ \\
\hline 7 & $\begin{array}{l}\text { Tentei responder à questão de uma forma geral, considerando o trabalho com a } 1^{\mathrm{a}} \text { e a } 3^{\mathrm{a}} \text { séries. Na } \\
\text { primeira série, como o idioma estava sendo introduzido e houve a especificidade de termos turmas } \\
\text { divididas, enfatizei mais a pronúncia do que na } 3^{\mathrm{a}} \text {, cujo trabalho foi mais voltado para a compreensão } \\
\text { textual. }\end{array}$ \\
\hline 8 & $\mathrm{X}$ \\
\hline
\end{tabular}

Ao analisarmos a tabela 7, vale retomar os comentários relativos ao quadro 6: dois professores excluem por completo de suas aulas o trabalho com as habilidades orais e com a pronúncia. Um deles é o entrevistado 5, que justifica essa exclusão por conta das "características das turmas", que "inviabilizam qualquer trabalho de compreensão auditiva ou expressão oral". Cremos que o entrevistado, ao usar o termo "características", se refira, entre outras possibilidades, à quantidade de alunos em sala, em geral, por volta de 30 alunos.

A última pergunta, de número 7 , "Caso você tenha trabalhado a pronúncia com seus alunos no Colégio Pedro II no ano de 2016, explique como e indique a frequência", busca detalhes dos procedimentos metodológicos empregados nas aulas de pronúncia e em que momentos se dava tal atividade.

\begin{tabular}{|c|c|}
\hline 1 & $\begin{array}{l}\text { Sempre pedia para ler textos em sala de aula, fazia um parêntesis sobre a pronúncia de determinadas } \\
\text { palavras. Com outro grupo que montou uma peça teatral, deixamos uma aula para trabalhar a } \\
\text { pronúncia de suas falas. Ao apresentar filmes, mostrei como os atores pronunciavam as palavras. Ao } \\
\text { escutar música de cantores de diferentes nacionalidades, atentei para a diferença de sotaque. Sempre ao } \\
\text { apresentar palavras novas, dizia as diferentes possibilidades de pronúncia e onde são mais comuns. }\end{array}$ \\
\hline 2 & $\begin{array}{l}\text { Não trabalhei especificamente, porque o foco nesse tema costuma ser na } 1^{\mathrm{a}} \text { série. Como não tive } \\
\text { turmas, não houve o momento dedicado especificamente para esse tema nas turmas de } 2^{\mathrm{a}} \text { e } 3^{\mathrm{a}} \text { séries. }\end{array}$ \\
\hline 3 & $\begin{array}{l}\text { Basicamente o processo se deu através de leitura de texto em sala. Tivemos uma apresentação de poesia } \\
\text { em que o aluno deveria ler alguns versos. Também dividimos o trabalhos de leitura do livro didático de } \\
\text { modo a permitir que todos leiam. Durante essas leituras, sempre que necessário, eu fazia apontamentos. }\end{array}$ \\
\hline 4 & $\begin{array}{l}\text { Nas turmas de 1a série, comecei o ano apresentando os sons do espanhol. Ao longo do ano, em todas } \\
\text { as turmas, utilizei a seção do livro adotado que trabalhava esse aspecto, ao final de cada unidade. Por } \\
\text { fim, tratava do assunto sempre que algum aluno apresentasse um problema, fosse na leitura ou na fala }\end{array}$ \\
\hline
\end{tabular}




\begin{tabular}{|c|c|}
\hline & espontânea. \\
\hline 5 & $\mathrm{X}$ \\
\hline 6 & 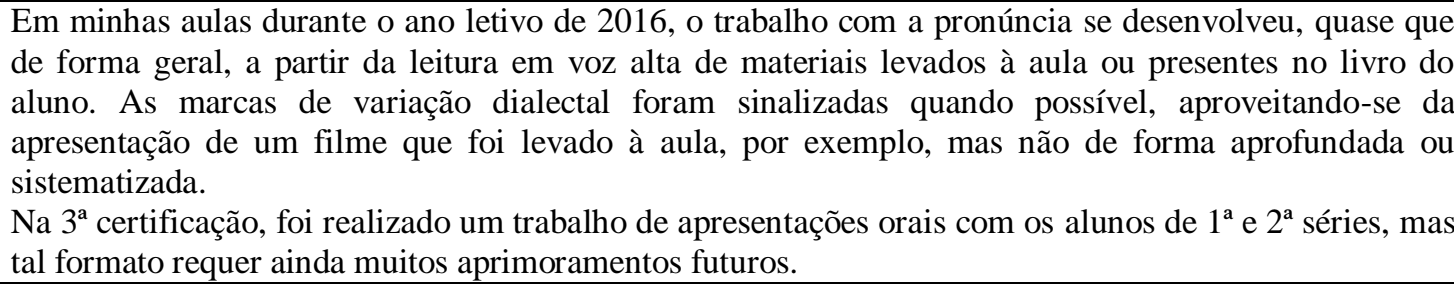 \\
\hline 7 & $\begin{array}{l}\text { Como comentado na questão anterior, tive a oportunidade de trabalhar mais a pronúncia na } 1^{\text {a }} \text { série. As } \\
\text { aulas, em grande parte, foram ministradas em espanhol e os alunos foram também estimulados se } \\
\text { expressar no idioma. Como parte da pontuação para compor a nota das } 3 \text { certificações, realizei testes } \\
\text { orais com as turmas, além de um teste de compreensão auditiva com base em um curta-metragem. O } \\
\text { último teste oral consistiu em um diálogo em duplas (elaborado em sala e gravado em áudio em casa) } \\
\text { também baseado em um curta-metragem. }\end{array}$ \\
\hline 8 & $\begin{array}{l}\text { Os alunos relutaram um pouco quando lhes exigia atividades que envolviam a pronúncia. A maioria } \\
\text { comentava que sentia vergonha de falar errado. A oralidade era mais praticada nas apresentações de } \\
\text { trabalhos em grupo e quando os estudantes faziam exercícios de compreensão auditiva e assistiam a } \\
\text { vídeos, pois tinham que elaborar comentários sobre os conteúdos que lhes foram apresentados. }\end{array}$ \\
\hline
\end{tabular}

Tabela 8. Respostas à pergunta 7: "Caso você tenha trabalhado a pronúncia com seus alunos no Colégio Pedro II no ano de 2016, explique como e indique a frequência”.

Quanto às atividades de pronúncia desenvolvidas em aula, optamos por limitar o período de análise ao ano de 2016, o ano anterior à pesquisa, por conta de comentários que nos fizeram confirmar que o direcionamento dos professores para suas atividades não se repete, necessariamente, em todos os anos. Anteriormente, por exemplo, havíamos ouvido o seguinte comentário de uma professora: "Minhas turmas este ano são muito pequenas. Viro as cadeiras e trabalho como se fosse um curso".

Em resposta à questão 7, verificamos que dois entrevistados (2 e 5) assumem não terem trabalhado com a pronúncia no período em questão. $\mathrm{O}$ entrevistado 2 comentou que limita as atividades de pronúncia à $1^{\mathrm{a}}$ série, com a qual não trabalhou em 2016. Dessa forma, as turmas de $2^{\mathrm{a}}$ e de $3^{\mathrm{a}}$ séries não foram contempladas com tais atividades, tratamento dado, aliás, com bastante frequência à pronúncia em aulas de línguas estrangeiras, independente da língua: apresentação dos sons no começo do $1^{\circ}$ período/ciclo/curso e completo esquecimento nos seguintes.

Ao considerar as respostas dos 6 entrevistados que afirmaram ter trabalhado com pronúncia ( $75 \%$ do total), verificamos que a situação mais recorrente é a correção durante a leitura de textos escritos: esse comportamento se observa nos entrevistados 1 , 3, 4 e 6. Retomemos aqui outro comentário de Derwing e Munro (2005, apud USÓ VICIEDO, 2008): se os professores, em sua formação, não receberam uma preparação formal quanto ao tratamento da pronúncia, é comum que foquem em traços muito específicos.

Percebemos uma possível incoerência na fala dos entrevistados 7 e 8 , ao afirmarem que trabalham a pronúncia quando desenvolvem atividades de compreensão e de expressão oral. É possível que façam correções durante a fala espontânea, mas também é possível que estejam considerando que, pelo simples fato de estarem trabalhando habilidades orais, estão trabalhando pronúncia; neste último caso, parecenos, faltariam atividades de um ensino explícito de pronúncia. $\mathrm{O}$ entrevistado 8 chega a afirmar que "os alunos relutaram um pouco quando lhes exigia atividades que envolviam a pronúncia", por vergonha de falarem errado. Isso significa dizer que eles relutaram em TODAS as atividades de expressão (e também de compreensão!) oral, uma vez que todas elas dependem da pronúncia. 
Os entrevistados 1 e 6 , além da prática predominante de corrigir pronúncia durante a leitura, também se ocuparam de variações regionais, a partir de filmes. $\mathrm{O}$ entrevistado $1 \mathrm{fez}$ uma atividade de conscientização dos sons, ao trabalhá-los com os alunos para uma apresentação teatral.

Por fim, o entrevistado 4 apresentou todos os sons em nível segmental no começo do ano para a $1^{\text {a }}$ série, mas continuou abordando o tema ao utilizar a seção específica do livro ao longo do ano para todas as séries, ou seja, realizou um trabalho constante, que contribui para eliminar dúvidas que persistam e ajudar os alunos a desenvolverem uma consciência fonético-fonológica. Além disso, corrigia os alunos sempre que apresentavam problemas, fossem eles na leitura ou na fala espontânea. Ao que parece, porém, limitou-se ao plano segmental, desconsiderando os aspectos prosódicos.

\section{Comentários Finais}

Ao longo do trabalho, uma contradição chamou a atenção: a discrepância entre a importância atribuída à oralidade (o que inclui a pronúncia) e sua efetiva prática nas aulas da educação básica. Considerando os dados com que trabalhamos (que coincidem com outras pesquisas já realizadas), um dos fatores que levam a essa situação de exclusão de atividades de pronúncia nas aulas de Espanhol são deficiências na formação docente, o que pode acarretar em desconhecimento do conteúdo. Somam-se a esses fatores dificuldades no desenvolvimento da prática desse conteúdo. O que se percebe é que há uma necessidade real de aprimoramento docente, de forma a contribuir para o desenvolvimento de habilidades tão importantes para a comunicação nos dias atuais e que correspondem aos anseios discentes.

\section{Referências}

AURRECOECHEA MONTENEGRO, Edith. La pronunciación: Su tratamiento en el aula E/LE. In: Red Electrónica de Didáctica del Español como Lengua Extranjera. Biblioteca 2009 número 10. Primer semestre. Disponível em: www.mecd.gob.es/redele/Biblioteca-Virtual/2009.html. Acessado em 23/09/15.

FARIAS, Maria Solange de. O ensino da pronúncia nos manuais de espanhol como língua estrangeira. In: Anais do SIEL 2015. Disponível em uece.br/eventos/siel2015/anais/trabalhos.html. Acesso em 04/07/17.

GIL FERNÁNDEZ, J. Fonética para profesores de español: de la teoría a la práctica. Madrid: Arco Libros, 2007.

LIMA JÚNIOR, Ronaldo Mangueira. Uma investigação dos efeitos do ensino explícito da pronúncia na aula de inglês como língua estrangeira. In: Revista Brasileira de Linguística Aplicada, v. 10, n. 3, Belo Horizonte, 2010. Disponível em www.scielo.br/scielo.php?script=sci_issuetoc\&pid=198-

639820100003\&Ing=pt\&nrm=iso. Acesso em 30/11/15. 
OLIVEIRA, Mirella Novais e KAUARK, Fabiana da Silva. Fonética e fonologia: aulas de pronúncia de E/LE no Brasil. In: Práxis Educacional, Vol. 7, No 11 (2011): Políticas Públicas em $\quad$ Educação. $\quad$ Disponível em periodicos.uesb.br/index.php/praxis/issue/view/50/showToc. Acesso em 21/07/15.

PINHO, José Ricardo Dordron de. Dando voz aos alunos - Repensando o ensino de Espanhol no Colégio Pedro II a partir das expectativas docentes. In: Inovações Pedagógicas (Coleção O novo velho Colégio Pedro II, Vol. 4). Rio de Janeiro: Colégio Pedro II, 2017.

POCH OLIVÉ, Dolors. Los contenidos fonético-fonológicos. In: SÁNCHEZ LOBATO, Jesús y SANTOS GARGALLO, Isabel. Vademécum para la formación de profesores: Enseñar español como segunda lengua (L2)/lengua extranjera (LE). Madrid: SGEL, 2008.

SOUZA, Marcela Ortiz Pagoto de. A fonética como importante componente comunicativo para o ensino de língua estrangeira. In: Prolíngua V. 2, N. 1 - Jan./Jun. de 2009. Disponível em ufpb.br/ojs2/index.php/prolingua. Acesso em 13/07/15.

USÓ VICIEDO, Lidia. La enseñanza de la pronunciación en LE: algunas consideraciones a tener en cuenta. In: Phonica, vol. 4, 2008. Universitat de Barcelona. Disponível em www. Publicacions.ub.edu/revistes/phonica4/. Acesso em 18/05/16.

Recebido em 29 de outubro de 2019

Aceito em 28 de março de 2020 